\title{
Notice of Duplicate Publication
}

Published online: 4 September 2021

(c) Dr. K C Chaudhuri Foundation 2021

The Editor-in-Chief would like to alert readers that due to an administrative error this article [1] has been republished in the same journal. The correct citations for this article should be from the original publication [2].

\section{References}

1. Shrivastava S. Timing of surgery/catheter intervention in common congenital cardiac defects. Indian J Pediatr. 2000;67(4):273-7.

2. Shrivastava S. Timing of surgery/catheter intervention in common congenital cardiac defects. Indian J Pediatr. 2000;67(3 Suppl):S2-6.

Publisher's Note Springer Nature remains neutral with regard to jurisdictional claims in published maps and institutional affiliations. 